\title{
Smart Bio-Polymeric Matrix for Accelerated Wound Healing and Tissue Regeneration
}

Dhasmana $A^{1,2 *}$, Singh $L^{3}$ and Malik $S^{4}$

${ }^{1}$ Department of Polymer \& Process Engineering, Indian

Institute of Technology Roorkee, India

${ }^{2}$ Department of Biotechnology, School of Applied and Life

Sciences, Uttaranchal University, India

${ }^{3}$ Department of Pharmacology, Kharvel Subharti College

of Pharmacy, India

${ }^{4}$ Department of Biotechnology, Amity Institute of Biotechnology, Amity University J harkhand, Ranchi, J harkhand, India

*Corresponding author: Archna Dhasmana, Department of Polymer \& Process Engineering, Indian Institute of Technology Roorkee, India; Department of Biotechnology, School of Applied and Life Sciences, Uttaranchal University, Dehradun, Uttarkhand-248007, India

Received: September 01, 2021; Accepted: October 08, 2021; Published: October 15, 2021

\begin{abstract}
Traditionally in Chinese medicine, animal sources and their by-products widely used for surgical and healing purposes. Eggshell Membrane (ESM) has been potentially used as grafting material for wound covering and healing due to its fibrous mesh enriched with collagen and glycoproteins. However, the fragile nature of ESM limits applicability for small and superficial wounds. Therefore, acellular matrix/scaffold fabricated from the allogeneic or xenogeneic tissues widely used as grafting material for the repairing and regeneration tissue. Here, we modified an acellular scaffold in different concentrations of ESM protein (ESMP)-5, 7.5 and 10\%, and studied synergistic effect for intensifying the tissue healing and regeneration process. Modified Scaffolds (ESMP-AGDS) were evaluated for tissue regeneration by subjecting it through physicochemical and biological characterization i.e., biochemical assay, FTIR, FESEM, in vitro and in vivo analysis. The study revealed proper interaction between the ESMP and acellular matrix 3D interconnected pores structure $(57.69 \pm 15.65 \mu \mathrm{m})$ with good porosity $(60.56 \pm 9.78 \%)$ for better cell and nutrient diffusion. In vitro studies revealed good biodegradability and biocompatibility of modified scaffold with 3T3 mouse fibroblast cells. At the very least concentration of $5 \%$ ESMP, acellular matrix showed excellent proliferation and attachment of fibroblast with the progression of time. Similarly, in vivo study showed a full-thickness excisional wound in the albino mice model healed within 14 days along with hair follicles regenerated neo-skin tissue, without any immunogenicity and inflammation. Thus, the study confirmed ESMP and acellular matrix synergistic effect results in a cost-effective, biodegradable, biocompatible smart material potentially applicable for tissue regeneration.
\end{abstract}

Keywords: Eggshell membrane; Cadaver goat-skin; Acellular scaffold; Skin; Wound healing; Tissue engineering

\section{Introduction}

Eggshell Membrane (ESM) is a natural biopolymer similar to native ECM, which is widely used as biotemplate for wound healing applications [1,2]. ESM mainly consist of $80-85 \%$ organic matter (70$75 \%$ are glycoproteins i.e., hyaluronic acid, sialic acid, GAGs, and $10 \%$ collagen $\mathrm{I}, \mathrm{V}$ and $\mathrm{X}$ ), which aid in would healing process $3-5$. ESM protein (ESMP) is biocompatible and biodegradable. Besides, it has anti-ageing, antimicrobial and anti-inflammatory property $[3,6,7]$. The potential value of ESMP is huge, especially in biomedical applications, viz., skin grafts, wound healing, plastic surgery, dental implants, angioplasty sleeves, cornea repair, treatment of osteoporosis as well as food casings and film emulsions [2]. Several researchers demonstrated the ESM as an ideal scaffold [8-10]. Yang and co-workers experimentally proved that ESM shows antiinflammatory response and significantly better wound healing rate as compared to commercially available skin-substitute (Biobrane ${ }^{\mathrm{TM}}$ ) [8]. Thus ESMP or ESM, containing various wound healing growth factors, is a potential biomaterial for wound healing, and an ESM or ESMP based skin-graft will be a promising skin substitute $[3,10$ 13]. However, the ESM is very thin, difficult to handle and lacks in flexibility and durability, which limits its applicability for large area wound coverage and treating full thickness wounds. On the other hand, skin grafts can easily be developed by decellularizing cadaveric allogeneic and xenogeneic skin, which can be applied for large area wound coverage and treating full thickness wounds. Some acellular skin grafts are already available in the market, e.g., OrCel', Apligraf, Matriderm', Permacol ${ }^{\mathrm{TM}}$ and Oasis" [14-17]. During decellularization of native tissue, there is a loss of biomolecules to some extent, which results in loss of bioactivity of the acellular skin graft-reducing the overall wound healing potential of the graft [16]. To overcome the above limitation and to enhance the graft's bioactivity, many scientists have designed growth-factor incorporated grafts [18-21]. But, the high cost of growth-factors limits its applicability for tissue engineering applications. The tissue sources, used to fabricate largesized acellular skin grafts, include mainly porcine, bovine and caprine (goat) [20-25]. Among these three, goat tissue is less immunogenic and less susceptible to viruses and prions, and had not yet been reported about transmission of any cattle disease to human [26,27]. Therefore, skin graft from cadaveric goat tissue will be a better and safer alternative in comparison to the porcine or bovine-based graft. Combination of ESMP with acellular ECM rich graft (ESMP-AGDS) will synergistically accelerate the wound healing and overcome the limitations of the ESM and acellular grafts. Moreover, the graft can be used for repairing/regenerating full thickness wound of large area. The ESMP-AGDS will be cost-effective as both the ESMP and AGDS is cheap and easily available. Therefore, in this study, we want develop 
an ESMP-AGDS hybrid skin graft which will be a cost-effective solution for rapid repairing/regenerating full thickness wound of large area.

\section{Experimental}

\section{Materials}

Raw eggshells were collected from the Campus's Hostel mess, under aseptic condition. For the fabrication of acellular dermal graft, fresh cadaver goat-skin was brought from slaughterhouse. All the reagents/chemicals of animal grade (nutrient culture media, buffers, enzymes, antibiotics) for graft fabrication and characterization were purchased from Himedia, India. Other solvents-acetic acid, dimethyl sulphoxide, chloroform, methanol, ethanol, phenol, isoamyl alcohol, formaldehyde solution were purchased from Sigma Aldrich.

\section{Preparation and characterization of soluble ESMP}

Raw membrane-bound eggshells were collected from mess were immediately cleaned them with deionized water. Cleaned eggshell immersed in $70 \%$ aqueous Acetic Acid $\left(\mathrm{CH}_{3} \mathrm{COOH}\right)$ for $24 \mathrm{~h}$ under continues mixing on magnetic stirrer to dissolve residual eggshell. Separated ESM were rinsed with deionized water repeatedly and dried in the oven at $50^{\circ} \mathrm{C}$. ESM was further ground to prepare fine powder using cryomill. After that soluble ESMP was prepared following the protocol as explained earlier by Strohbehn and coworkers [28]. Briefly, ESM powder was dissolved in alkaline solution of $12 \%$ Sodium Hydroxide $(\mathrm{NaOH})$ for $12 \mathrm{~h}$ at $37^{\circ} \mathrm{C}$. Subsequently, dissolved ESM solution was centrifuged to precipitate the remaining calcium carbonate $\left(\mathrm{CaCO}_{3}\right)$ and neutralize separated the supernatant containing soluble ESMP ( $\mathrm{pH} 7$ ) with $10 \% \mathrm{CH}_{3} \mathrm{COOH}$ solution at $4^{\circ} \mathrm{C}$. The ESMP solution was freeze dried and molecular weight was determined by SLS by following the protocol explained earlier by other researchers [21,29]. Briefly, the molecular weight of soluble ESMP was determined by Static Light Scattering (SLS) on a Wyatt EOS $(\lambda)$ at $682 \mathrm{~nm}$ wavelength, multiangle light scattering detector, operated in batch mode with water as solvent at room temperature.
ESMP solution serial diluted in different concentration and all the samples were syringe filtered (PTFE filter, $0.22 \mu \mathrm{m}$ ) before analyzing and determined using high sensitivity of the detector. The refractive index increment was measured with differential refractometer DnDc2010 (WGE Dr. Bures) and Differential refractometer Software Ver. 3.24 (Brookhaven Instruments). SLS data were obtained by using a self-built of the laser scattering system. By using Zimm plot (plotted the intensity of the scattered light against the scattering angle) the weight-average Molecular Weight (Mw), Radius of Gyration (Rg), and second virial coefficient $\left(\mathrm{A}_{2}\right)$ of the prepared sample was determined.

\section{Fabrication of hybrid ESMP-AGDS}

Acellular Goat-Dermal Scaffold (AGDS) was fabricated using physio-chemoenzymatic methods [21]. Briefly, after removal of hair, epidermis and subcutaneous tissue from the native cadaver goatskin, dermis was subjected to decellularization. The native dermal tissue was placed in the solution containing $0.25 \%$ Trypsin-EDTA in $1 \mathrm{X}$ PBS and $1 \%$ antibiotic (antimycotic) for $12 \mathrm{~h}$ at $25^{\circ} \mathrm{C}$. The tissue sections were further treated with $0.1 \%$ SDS in $1 \mathrm{X}$ PBS for $6 \mathrm{~h}$ at $37^{\circ} \mathrm{C}$, subsequently followed by agitating in enzymatic solutionRNase $(20 \mu \mathrm{g} / \mathrm{ml})$ and DNase $(0.2 \mathrm{mg} / \mathrm{ml})$ solution in $1: 1$ ratio for $24 \mathrm{~h}$ at $37^{\circ} \mathrm{C}$. Finally, thoroughly washed the obtained acellular dermal scaffold with $1 \mathrm{X}$ PBS by gently shaking and then lyophilized it. Dried scaffold pieces were sterilized with $70 \%$ ethanol for $30 \mathrm{~min}$ followed by UV $(\lambda=260 \mathrm{~nm})$ treatment for $4 \mathrm{~h}$. ESMP modified acellular scaffold (ESMP-AGDS) pieces were fabricated by dip coating or soaking them in different concentration of ESMP solution- 5\%, $7.5 \%$ and $10 \%$ for $30 \mathrm{~min}$ and subsequently divided them as sample 1, 2 and 3 respectively (Figure 1). After ESMP coating modified acellular scaffold were then removed from the respective solutions and lyophilized. All the lyophilized hybrid ESMP-AGDS samples were stored and characterized for wound healing and tissue regeneration.

\section{Porosity}

Porosity $(\chi)(n=5)$ were determined by following the liquid displacement method protocol as described by Sharma et al [30].

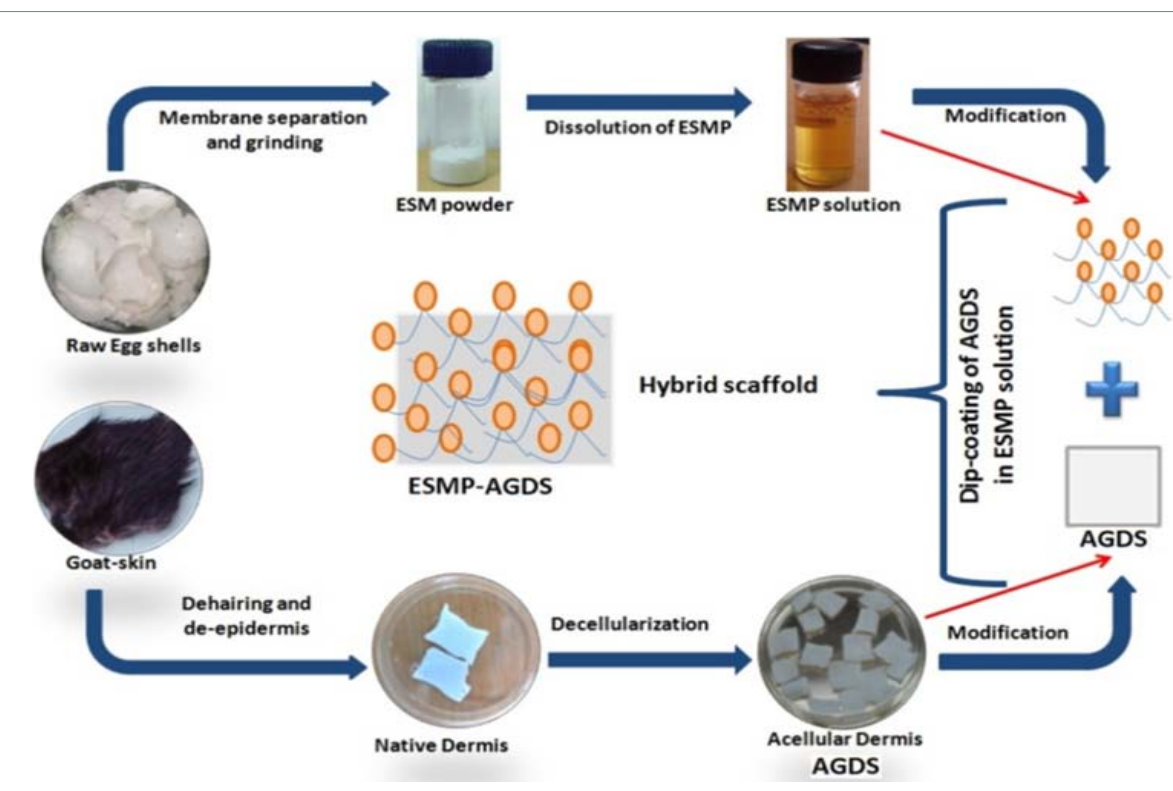

Figure 1: Schematically representation of the ESMP-AGDS hybrid skin graft the fabrication process. 
To determine the volume of pores within the scaffold, the amount of solvent filled in the porous scaffold structure, was calculated. In brief, the scaffold is completely immersed in graduated cylinder filled with a known volume of water $\left(V_{1}\right)$ and the volume of water after the scaffold-immersion was recorded as $V_{2}$. After immersion, the scaffold was removed and the volume of solvent remaining in the graduated cylinder was measured as $V_{3}$. Further, the total volume $\left(V_{t}\right)$ of the scaffold was calculated to determine porosity $\chi$ following the equations as described below.

$$
\begin{aligned}
& \chi=\frac{V_{1}-V_{3}}{V_{t}} \times 100 \\
& \mathrm{~V}_{\mathrm{t}}=\mathrm{V}_{2}-\mathrm{V}_{3}
\end{aligned}
$$

All the experiments the mean value and Standard deviation (mean $\pm \mathrm{SD}$ ) was calculated.

\section{Morphological characterization}

Ultra-structure of the AGDS (control) and hybrid ESMP-AGDS including porosity and pore size was determined using Field-Emission Scanning Electron Microscopy (FESEM) (MIRA3 TESCAN, BrnoKohoutovice Czech Republic). Images of the upper surface and crosssectional area of grafts were examined at the saturation pressure of 1 torr and $5 \mathrm{kV}$ accelerating voltage. Further, the scaffolds average size of pores and porosity were determined using ImageJ software (Image J 1.40 g, Wayne Rasband, National Institute of Health, USA).

\section{Chemical characterization}

Fourier Transform Infrared Spectroscopy (FTIR) analysis of the ESMP, AGDS and hybrid ESMP-AGDS were performed for the functional group and secondary structure analyses of proteins. All the samples were processed to form compressed $\mathrm{KBr}$ pellets in ratio of $1 \mathrm{mg}$ sample per $900 \mathrm{mg} \mathrm{KBr}$. The absorbance of the samples were recorded in the range from 4000 to $400 \mathrm{~cm}^{-1}$ at $2 \mathrm{~cm}^{-1}$ resolutions using FTIR spectrophotometer (Thermo Nicolet, USA) and recorded the absorbance averaging 100 scans.

\section{Crosslinking test (Ninhydrin assay)}

Degree of crosslinking in fabricated scaffolds was determined by Ninhydrin assay [31]. In this assay, ninhydrin reacts with free amino group present in sample gives a deep blue or purple color. Briefly $50 \mathrm{mg}$ of sample was taken in test-tube and $1 \mathrm{ml}$ ninhydrin reagent was added in it. Mixed the sample and ninhydrin by vortexing and boiled for $2 \mathrm{~min}$ by keeping them in pre-warmed water bath. After boiling samples were cooled down at RT and $1 \mathrm{ml}$ ethanol (50\%) was added. Samples were mixed well and absorbance was measured at $570 \mathrm{~nm}$. Glycine solution was taken as standard, unmodified scaffold (Non crosslinked-NC) as control and crosslinked sample (C). The degree of cross-linking was calculated by the formula described below:

$$
\text { Crosslinking index }(\%)=\frac{(\text { OD of NC-OD of C })}{\text { OD of NC }} \times 100
$$

\section{In vitro biodegradation}

The biodegradability rate of the AGDS and hybrid ESMPAGDS were evaluated under enzymatic as well as under nonenzymatic conditions [2]. Briefly, $2 \mathrm{mg}$ scaffold pieces were weighed and immersed in $10 \mathrm{~mL}$ of $1 \mathrm{X}$ PBS enzymatic solution having 0.05\% collagenase enzyme from Clostridium histolyticum for study the biodegradation. Similar for the evaluation of non-enzymatic degradation, samples were immersed in $1 \mathrm{X}$ PBS ( $\mathrm{pH}$ 7.4). Both the enzyme treated and non-treated samples were incubated at $37^{\circ} \mathrm{C}$ in a shaking incubator and after regular time intervals of $5 \mathrm{~h}$, the samples were removed from the shaker, lyophilized and weighed. Weight loss or the rate of biodegradation $(n=3)$ was calculated by using the following equation:

$$
\text { weight loss } \%=\frac{W_{o}-W_{t}}{W_{o}} \times 100
$$

where, $W_{o}$ denotes the initial weight of the scaffold and $W_{t}$ denotes the weight of the degraded scaffold at different time intervals.

\section{Biocompatibility study}

MTT assay: The cell viability and proliferation over the scaffold was studied by MTT assay with 3T3 mouse fibroblast cell line. Briefly, the sterilized AGDS (control) and hybrid ESMP-AGDS pieces of dimension $1 \mathrm{~cm} \times 1 \mathrm{~cm} \times 1 \mathrm{~mm}$ were kept in a 24 -well tissue culture plate containing DMEM nutrient medium and incubated overnight in a $\mathrm{CO}_{2}$ incubator. After the incubation, nutrient medium was removed from each well and $10 \mu \mathrm{l}$ of cell suspension $(1 \times 103$ cells/well $)$ medium was added to the scaffold present in the well. Further, $990 \mu \mathrm{l}$ fresh DMEM medium was added in the wells incubated in the $\mathrm{CO}_{2}$ incubator $\left(5 \% \mathrm{CO}_{2}\right.$ supply) at $37^{\circ} \mathrm{C}$. After respective time period of 1 , 3, 5 and 7 day, MTT assay was performed and the absorbance of the sample was measured. The experiment was carried out in triplicates. For MTT assay, at different time periods, freshly prepared DMEM media and MTT $(5 \mathrm{mg} / \mathrm{ml}$ stock in $1 \times$ PBS), were added in the ratio $(\mathrm{v} / \mathrm{v})$ of 1:9 into the respective wells. The plates were incubated at $37^{\circ} \mathrm{C}$ in dark for $4 \mathrm{~h}$ and thereafter the media was removed from the wells. To dissolve the formazan crystals, $0.2 \mathrm{ml}$ DMSO was added in each well and gentle swirled the tissue culture plate. After the complete dissolution of formazan crystals, the absorbance of the samples were taken at wavelength of $490 \mathrm{~nm}$ using Microplate Reader (TECAN, India). The absorbance gives a measure of cell viability. The cellviability was calculated at different time intervals (days) by using the measured absorbance value.

Cell adherence and morphological examination by FESEM: Cell adherence and spreading over the scaffold was examined by FESEM image analysis of the recellularized scaffold by following the previous protocol [32]. On day 7, cell-seeded scaffold-constructs of both samples (AGDS and hybrid ESMP-AGDS-cell construct) were collected and fixed in $4 \%$ formalin solution. The formalin fixed scaffolds were then dehydrated using ethanol at $4^{\circ} \mathrm{C}$ in gradient concentration (50\%, 70\% and 100\%) for 30min each and overnight air-drying. Then, the outer surface and cross-sectional morphology of the scaffold was examined at the saturation pressure of 1torr and accelerating voltage of $5 \mathrm{kV}$. Images were captured by FESEM and analyzed by using ImageJ analysis software.

\section{Pre-clinical study}

For animal wound healing study the protocol was approved by the Institute Animal Ethics Committee (ethical approval number: BT/ IAEC/2016/02), IIT Roorkee, India. In vivo full thickness excisional wound healing experiment were performed by using procedure as described in the literature [33]. Two months old, 48 healthy albino mice (both sex) having weight 25-30 gm were procured from the animal house of IVRI, Bareilly. Animal were housed in the institute animal house and were supplied with food and ad lib water. All animals were kept separately, so they can live comfortably. 


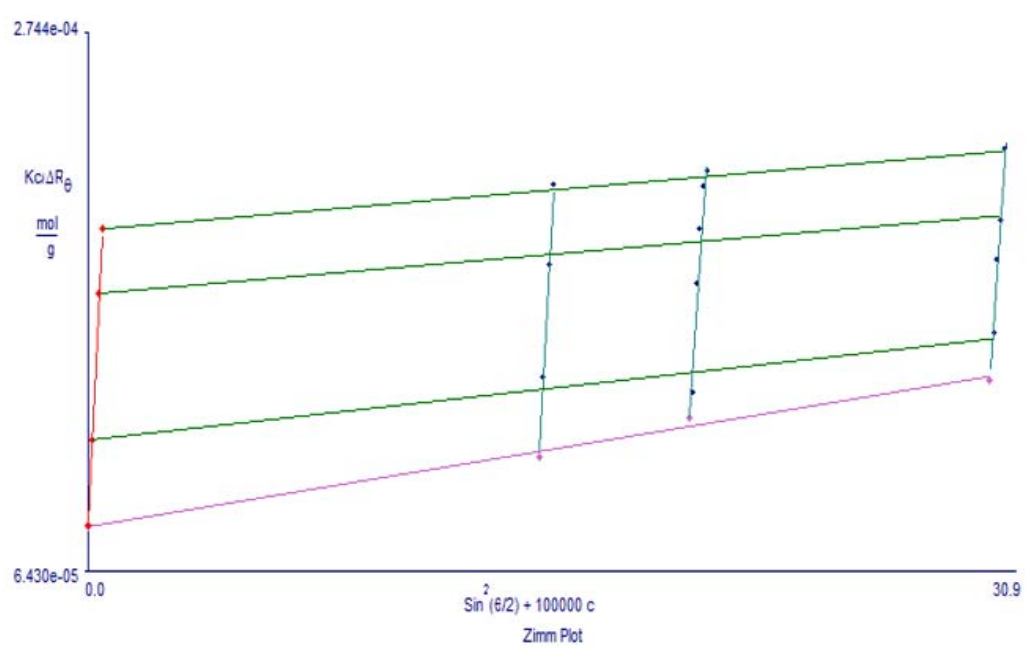

Figure 2: Molecular weight analysis of ESMP SLS analysis-Zimm plot (here red line-0 angle \& pink line- 0 concentration).

Wound construction and graft implantation: Wound creation was done aseptically under anaesthetic condition. Anaesthesia drug were administered to the animals by the IP route with dosage: diazepam, $10 \mathrm{mg} / \mathrm{kg}$ animal body weight and ketamine, $100 \mathrm{mg} / \mathrm{kg}$ of animal body weight. After anaesthesia, dorsal back side hair of the animal was shaved, cleaned with antiseptic solution (Dettol') and full-thickness excisional wound of diameter $1.5 \mathrm{~cm}$ was created by punching method. Subsequently, animals were divided into 3 groups (8 animals in each group) classifying them as: control (I): treatment with Povidone-iodine solution (Betadine', Win-Medicare Pvt. Ltd., India), unmodified scaffold (AGDS) (II) and modified scaffold (ESMP-AGDS) (III). Group I was treated with normal dressing, group II was treated with AGDS and group III was treated by grafting the modified scaffold on the wound site. After treatment, all the wounds were dressed with sterile non-adhesive surgical padCombine dressing (KS CARE ${ }^{\mathrm{TM}}$, India) and covered with surgical tape (3M Transpore ${ }^{\mathrm{TM}}$, North coast medical Inc. USA), for the prevention of dressing omission and proper aeration of wound area.

\section{Evaluation of wound healing:}

Wound healing rate: Wound healing area $\left(\mathrm{mm}^{2}\right)$ of all groups was measured on postoperative day of 3, 7 and 14. Transparent sheet was used for tracing the wound contraction area and graph paper was used to calculate the wound healing area. The wound healing \% was measured by mapping the size of wound reduction area during wound healing.

Planimetry: For the examination of shape, abnormality and colour of the wound, colour pictures of the wound site were taken with a digital camera from a fixed distance, on post-operative day of 3,7 and 14 .

Histology evaluation: Tissue biopsies samples were collected from the wound site on post-operative day 7 and 14. Collected biopsies were fixed in $10 \%$ formalin for $1 \mathrm{~h}$ and then embedded in paraffin. The fixed tissue was sectioned into $5 \mu \mathrm{m}$ thick slices and then mounted on glass-slide, followed by H\&E staining. After staining, images of the stained tissues were taken at 10X magnification using phase-contrast microscopy and the images were analyzed using Miotic Imaging software (Diagnostic Instruments; Sterling Heights, MI).

Immunological observations: In vivo immunogenic and allergic responses induced by AGDS and hybrid ESMP-AGDS were evaluated by measuring the Immunoglobulin (Ig) level, Complement component (C3) and specific inflammatory cell level by following the protocol of Banrejee and co-workers [34]. Briefly, blood samples were collected on post-operative days of 7 and 14 from the mice tailvein and stored them at $-80^{\circ} \mathrm{C}$ until it's analyzed. In-direct ELISA was performed to measure the level of IgG, IgM and C3 in blood serum using an anti-mouse IgG which is primary antibody conjugated secondary antibody with horseradish peroxidase. For Complete Blood Counting $(\mathrm{CBC})$ testing, blood samples were collected in EDTA coated vials (to protect it from clotting) and subjected to analysis by Multispecies Haematology system (Siemens, Germany).

\section{Statistical analysis}

Experimental data quantitative results were measured as mean \pm standard deviation and statistically by the applying the Analysis of Variance (ANOVA) and p-value $(<0.05)$.

\section{Results and Discussion}

\section{SLS analysis of ESMP}

SLS method was used to determine the molecular weight of the prepared soluble ESMP by plotting the Zimm plot (Figure 2). Zimm plot of ESMP dissolved in water is plotted by 4 different concentration and 6 scattering angles $\left(0-105^{\circ}\right)$. The Molecular Weight $(\mathrm{Mw})$, Radius of Gyration $(\mathrm{Rg})$ and $2^{\text {nd }}$ viral of coefficient $\left(\mathrm{A}_{2}\right)$ was found to be $12 \mathrm{kDa}, 111.4 \pm 7.5 \mathrm{~nm}$ and $9.8 \pm 2.1 \mathrm{e}-02 \mathrm{~cm}^{3} / \mathrm{mol} / \mathrm{g}^{2}$. The low and positive value of $\mathrm{A}_{2}$ indicates the good solubility of sample in solvent. In literature, it was reported that ESMP fractions $(>10 \mathrm{kDa})$ helps to mitigate UV-B radiation-induced wrinkles, collagen, Hyaluronic Acid (HA), MMP-1 activity and can be used for functional cosmetic materials [35].

\section{Bio-chemical analysis}

Ninhydrin assay indicates with the crosslinking occurs between the ESMP and AGDS free functional group, and with the increase of concentration SF crosslinking percentage increases (Figure $3 \mathrm{~A}$ ). 

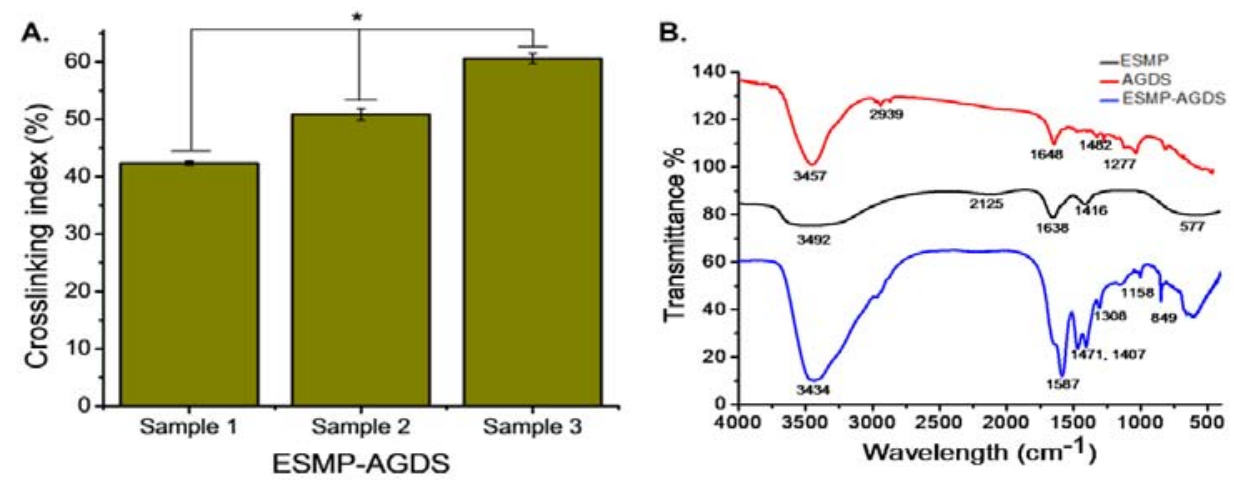

Figure 3: Biochemical characterization ESMP-AGDS: (A) Crosslinking index between ESMP and AGDS in ESMP-AGDS and (b) FTIR spectra analysis of ESMP AGDS and ESMP-AGDS.

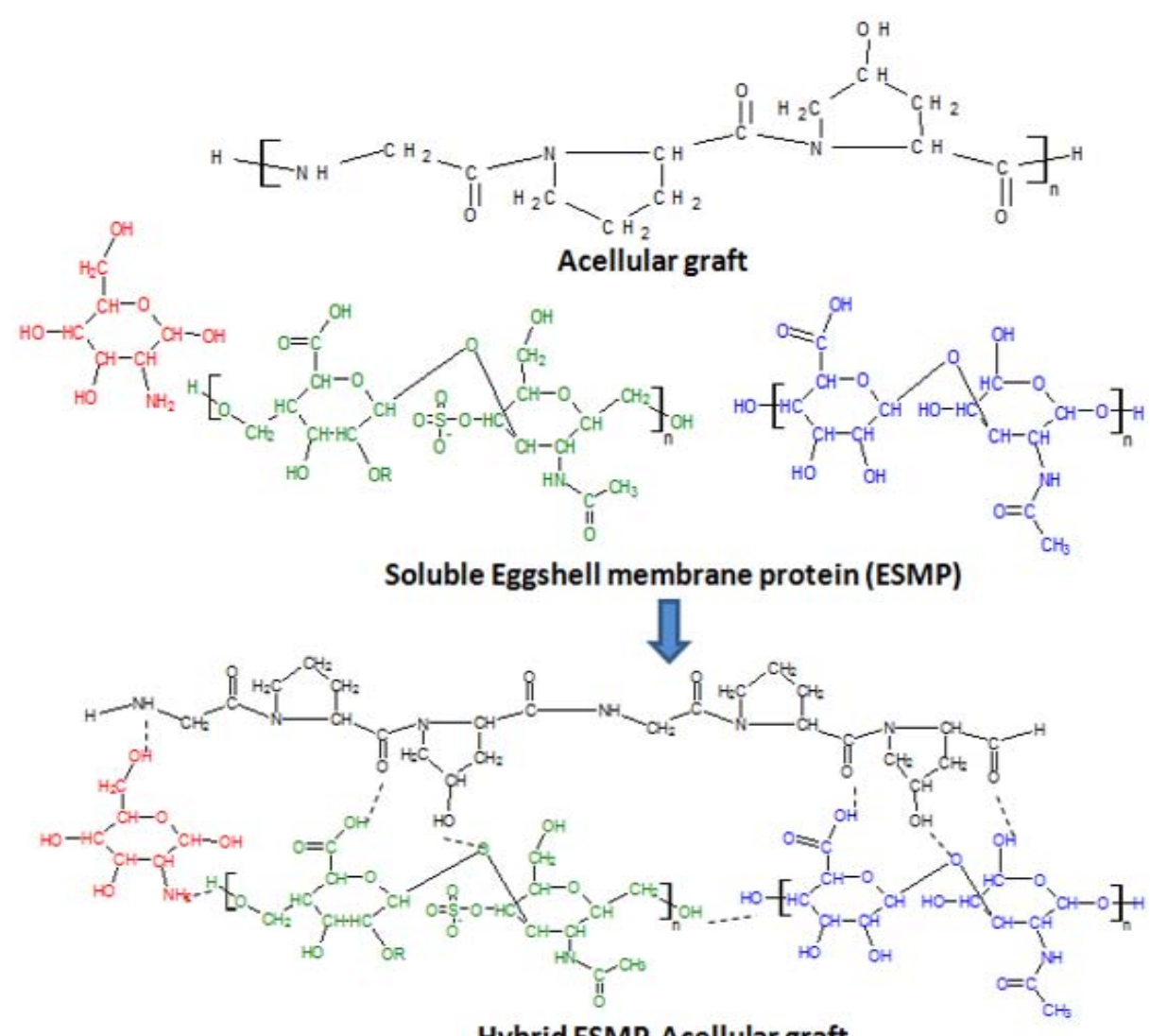

Hybrid ESMP-Acellular graft

Figure 4: Schematically diagrammatic representation of possible interaction between ESMP and AGDS (acellular graft).

FTIR spectra analysis of ESMP, AGDS and hybrid ESMP-AGDS was studied to determine the interaction occurs between the different the components used to fabricate the graft (Figure 3B). FTIR spectra of ESMP showed the presence of the characteristic peaks $3492 \mathrm{~cm}^{-1}$ between the region 3750 and $2500 \mathrm{~cm}^{-1}$, shows stretching mode of $\mathrm{O}-\mathrm{H}$ and $\mathrm{N}-\mathrm{H}$ group , asymmetric stretching vibration of $\mathrm{C}-\mathrm{H}$ bonds present in $=\mathrm{C}-\mathrm{H}$ and $=\mathrm{CH}_{2}$. Peak at $2125 \mathrm{~cm}^{-1}$ confirmed the $\mathrm{CH}$ stretching between the groups. The region of lower wavelength shows $\mathrm{CN}$ stretching/NH bending modes, assigned to the amide I, amide II and amide III vibrations of the glycoproteins, respectively. The peaks at 1638,1416 and $577 \mathrm{~cm}^{-1}$ corresponds to the stretching modes of
C-O, N-H and C-S bonds, respectively. Kang and co-workers reported the peaks at $3262 \mathrm{~cm}^{-1}$ of $\mathrm{NH}$ stretching vibration; $2968 \mathrm{~cm}^{-1}$ of $\mathrm{CH}$ stretching; $1642 \mathrm{~cm}^{-1}$ of CO amide I, and $1549 \mathrm{~cm}^{-1}$ of $\mathrm{NH}$ bending amide II in soluble ESMP $[11,36]$. Sah \& Parmanik found FTIR spectra peaks at $3215 \mathrm{~cm}^{-1}, 2126 \mathrm{~cm}^{-1}, 1654 \mathrm{~cm}^{-1}, 1545 \mathrm{~cm}^{-1}, 1253 \mathrm{~cm}^{-1}$ present in ESMP [37]. Likewise, other scientists also reported all the essential proteinceous compounds peaks at the region: $3200-3500 \mathrm{~cm}$ 1, $1600-1700 \mathrm{~cm}^{-1}$ (amide I), 1500-1600 cm-1 (amide II), 1200-1300 $\mathrm{cm}^{-1}$ (amide III) respectively [38-40]. FTIR spectra of AGDS have peaks at $3473 \mathrm{~cm}^{-1}$ for the $\mathrm{NH}$-stretching, $2923 \mathrm{~cm}^{-1}$ for asymmetrical $\mathrm{CH}_{2}$ stretching. Other peaks at the absorbance $1643 \mathrm{~cm}^{-1}, 1554 \mathrm{~cm}^{-1}$ 

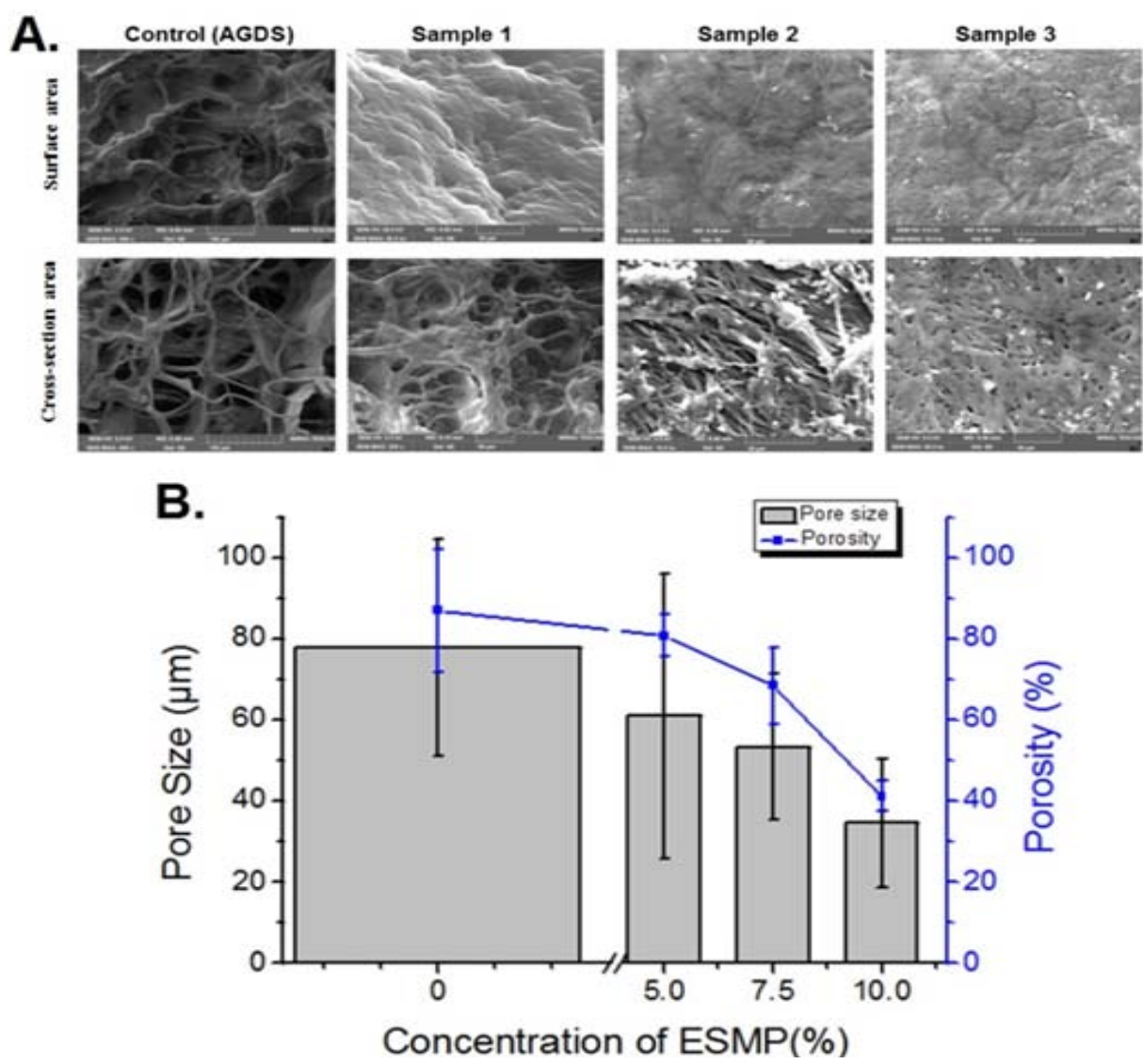

Figure 5: (A) FESEM images of unmodified (control-AGDS) and hybrid (ESMP-AGDS) with different concentration of ESMP protein. (B) Correlation between the concentration of ESMP protein in hybrid scaffold with the porosity and pore-size of the scaffold.

and $1240 \mathrm{~cm}^{-1}$ showed the presence of amide I $(\mathrm{C}=\mathrm{O})$, amide II $(\mathrm{NH})$ and amide III (CN) groups respectively, which proves the collagenous structure and the presence of functional groups for better cell attachment. In case of the hybrid ESMP-AGDS the peaks at $3434 \mathrm{~cm}^{-1}$ (stretching mode of $\mathrm{OH}, \mathrm{NH}$ group), $1587 \mathrm{~cm}^{-1}$ (amide I), $1471 \mathrm{~cm}^{-1}$ (amide II), $1158 \mathrm{~cm}^{-1}$ (amide III) were shifted, confirmed the possible interactions among the functional groups. Asymmetrical stretching $\mathrm{CH}_{2}$ group peak at $2939 \mathrm{~cm}^{-1}$ present in AGDS was disappeared after modification in the modified scaffold, which indicated the possible H-bonding or other interaction forms between the AGDS and ESMP. Other peaks at $1407 \mathrm{~cm}^{-1}, 1308 \mathrm{~cm}^{-1}$ and $849 \mathrm{~cm}^{-1}$ were appeared, which indicates the presence of $\mathrm{NH}, \mathrm{C}=\mathrm{O}, \mathrm{CS}$, functional groups on the surface for better cell attachment. Other researchers, also found shifting or disappearance of the native peaks in different ESMP composite with other polymers (PLGA, PEO,PVA, PCL,SF) which results stable cross-linking $[9,11,13,37,41]$. As mentioned above in FTIR spectra analysis, AGDS pieces were simply modified with soluble ESMP by dip-coating method indicates the possible interaction or chemical bonding occurs between the ESMP and AGDS. ESMP and AGDS have protein rich matrix, which results the crosslinking between the biomolecules or functional groups present on their surface (Figure 4). Acellular tissue matrix is mainly consists of collagen protein for the stable amide linkage between the groups. Similarly, the ESM have a protein rich structure consist of collagen, GAGs, proteoglycans $[42,43]$. In literature, many scientist modified the several polymeric scaffold (PCL, PLA, PVA, PEG etc.) with ESMP to enhance the biocompatibility by simple physical method and formation of $\mathrm{H}$-bonding with functional (amide and carbonyl) group on ESMP surface [44]. Here, we also assumed that the H-bonding occur between the amide and carbonyl groups of the ECM based acellular scaffold surface and ESMP.

\section{Morphological analysis}

FESEM images of the fabricated AGDS and hybrid ESMPAGDS showed pore to pore interconnected ultrastructure with good porosity (Figure 5 ). The porosity and pores size of the scaffold were significantly good after coating with ESMP. In case of AGDS, the pores size and porosity was found to be $77.69 \pm 26.81 \mu \mathrm{m}$ and $86.56 \pm 15.10 \%$. While in the case of hybrid ESMP-AGDS the pore size and the porosity of the scaffolds were progressively decreased, with the increase of concentration of ESMP solution. Among all the groups Sample 1, hybrid ESMP-AGDS with 5\% concentration ESMP, showed good porosity $60.56 \pm 9.78 \%$ and pore-size $57.69 \pm 15.65 \mu \mathrm{m}$, this is good for cell migration and proliferation. Other researcher proved that the scaffold have microstructure for better cell growth and nutrient diffusion [45-48]. Sah and co-workers found that the SFPVA (Silk Fibroin-Polyvinyl alcohol) scaffold modified with 2\% (w/v) soluble ESMP could be a better option for tissue engineering [49].

\section{Bio- degradability rate}

The degradability rate of grafts (AGDS and ESMP-AGDS) was 


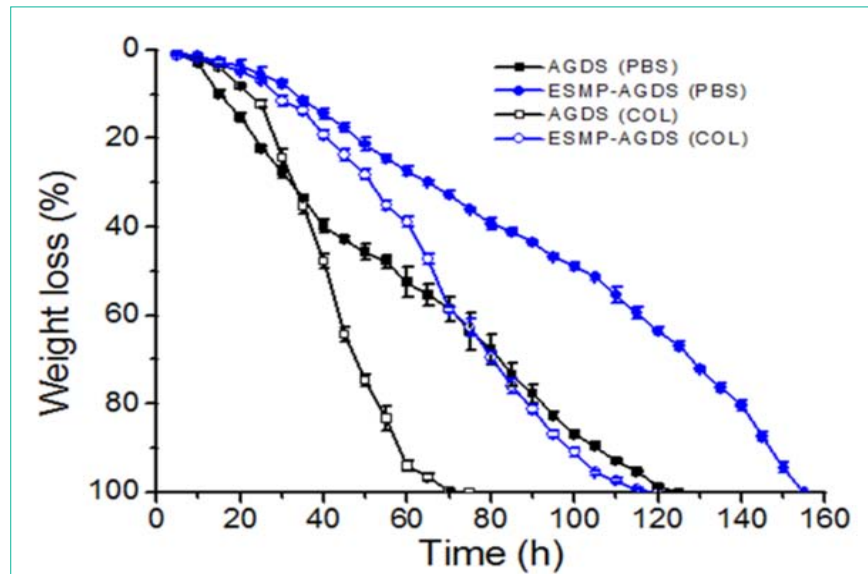

Figure 6: In vitro biodegradation of AGDS and ESMP-AGDS in the presence of Collagenase enzyme (COL) and 1 X PBS solution.

Table 1: Comparison of biodegradability rate of unmodified (AGDS) and ESMP modified acellular dermal scaffold.

\begin{tabular}{|c|c|c|c|}
\hline \multirow{2}{*}{ Scaffold Type } & ESMP concentration (\%) & \multicolumn{2}{|c|}{$\begin{array}{r}\text { Time for complete degradation } \\
\text { (h) }\end{array}$} \\
\cline { 2 - 4 } & & PBS (1X) & Collagenase (0.05\%) \\
\hline \multirow{2}{*}{ AGDS } & 0 & 125 & 75 \\
\hline \multirow{2}{*}{ ESMP-AGDS } & 5 & 160 & 120 \\
\cline { 2 - 4 } & 7.5 & 170 & 130 \\
\cline { 2 - 4 } & 10 & 175 & 135 \\
\hline
\end{tabular}

Table 2: Inflammatory response shown at the wound site of different treated groups on postoperative day 7 and 14 .

\begin{tabular}{|c|c|c|c|c|}
\hline Day & Control & Standard & AGDS & ESMP-AGDS \\
\hline 7 & 1.8 & 1 & 0.5 & 0.45 \\
\hline 14 & 1.25 & 0.75 & 0 & 0 \\
\hline
\end{tabular}

Here, the inflammatory response scored as: value " 0 " for little or no inflammation "1" for moderated or less inflammation and " 2 " for extensive.

evaluated under enzymatic (0.05\%) and non-enzymatic (PBS) conditions (Figure 6 and Table 1). Hybrid ESMP-AGDS complete degraded within $160 \mathrm{~h}$ under in PBS and $120 \mathrm{~h}$ in the presence of collagenase enzyme. After the addition of ESMP with AGDS, degradation time was significantly increased, which indicates that possibly some strong interaction from among them. In case of hybrid ESMP-AGDS matrix excessive deposition of ECM proteins occurs, which may results slow-degradation and more stability as compare to the AGDS. ESM and soluble ESMP has a high content of bioactive components, which are nontoxic and biodegradable [7,13,50]. Many researchers successfully synthesized ESMP composite scaffolds (e.g., SF-SEM, PEG-ESM, PCL-ESM) to hinders the biodegradability and increase their biocompatibility, without any toxic effect [37,44,51]. Here, we also observed the significant change in degradability of scaffold after modification, may be in results better tissue regeneration.

\section{In vitro biocompatibility study}

The compatibility of fabricated scaffold (AGDS and hybrid ESMP-AGDS) was evaluated by seeding the 3 T3 mouse fibroblast on it and measured the cell viability and proliferation by performing MTT assay (Figure 7A). MTT assay analysis was done by measuring the absorbance of the cell-scaffold construct, which showed that with the progression of time and increase in cell number, absorbance of the
Table 3: Immunogenic response induced in treated albino mice-control (Group I), AGDS (Group II) and ESMP-AGDS (Group III) at day 7 and 14.

\begin{tabular}{|c|c|c|c|c|c|c|}
\hline Day & 7 & 14 & 7 & 14 & 7 & 14 \\
\hline Type & \multicolumn{2}{|c|}{ IgG } & \multicolumn{2}{|c|}{ IgM } & \multicolumn{2}{|c|}{ C3 } \\
\hline Control & + & - & + & - & + & - \\
\hline AGDS & - & - & - & - & - & - \\
\hline ESMP-AGDS & - & - & - & - & - & - \\
\hline
\end{tabular}

Here + for high level and - for low level of Immunoglobin (Ig) and C3 molecule.

sample was consequently increased. The absorbance of hybrid ESMPAGDS was significantly higher as compared the AGDS (control), which indicates the progressively increased the cell proliferation with time. FESEM images analysis of the cell seeded scaffold on day 7 , showed cells were completely adhered and proliferated, over the surface and inside the pores of the scaffold (Figure 7B). Complete recellularization of scaffold concluded that the interconnected porous structure and ECM rich nature, results better cell growth and tissue regeneration. Yi and co-workers, reported that the cell culture tests showed that biocompatibility of SEP is comparable to collagen type I and even superior to raw ESM [3]. Several researchers have tried to demonstrate that ESMP is an ideal biocompatible scaffold material because of its similarity to native ECM [5,52,53] and applied Soluble Eggshell Membrane Protein (SEP) extracted from ESM used as a natural surface coating on a synthetic polymer (PE, PVA, PEO, PCL, PLGA) to enhance cell attachment $[3,13,54,55]$. Eggshell membrane-derived peptides prepared by alkaline treatment, were shown to stimulate human skin fibroblasts in vitro [56]. Qi and co-workers reported that the SEP/chitosan blend has much better biocompatibility-NIH 3T3cell, than pure chitosan [57]. OhtoFujita and co-workers found that immobilizing hydrolyzed egg membrane on phosphorylcholine polymer could provide an ECM environment for human dermal fibroblasts adhesion and growth [1]. In another studies, in vitro cytocompatibility and differentiation study SEP modified SF and SF-PVA scaffolds showed that showed that SEP supports viability, proliferation and differentiation of cord blood derived human mesenchymal stem cell $[37,49]$. This data revealed that at $5 \%$ concentration of ESMP coating scaffold showed best proliferation, because of stable and proper coating of pores in acellular scaffold. As reported in the literature by other scientist, we also found that the synergistic effect of ESMP along with AGDS provides a suitable microenvironment for better cell growth and neotissue regeneration.

\section{Wound healing study}

The full-thickness excisional wounds treated with AGDS and ESMP-AGDS (5\% ESMP) was studied the measure the in vivo biocompatibility and wound healing capability. The scaffolds (AGDS and ESMP-AGDS) were grafted over the wound and observed post-operative at different time interval. By macroscopic or visual observation, we observed that within 2 weeks the wounds were completely healed after treating them with acellular scaffolds, without any contraction or scarring at the wound site (Figure 8A). However, AGDS and ESMP-AGDS covered wounds showed significantly better wound healing rate i.e. group (II -88\% \& III-95\%) within 7 days (Figure 8B) and wounds were completely healed within 2 weeks. The healing rate and contraction of ESMP-AGDS treated wound is faster and regenerated skin tissue with hair-follicles as compared to the 


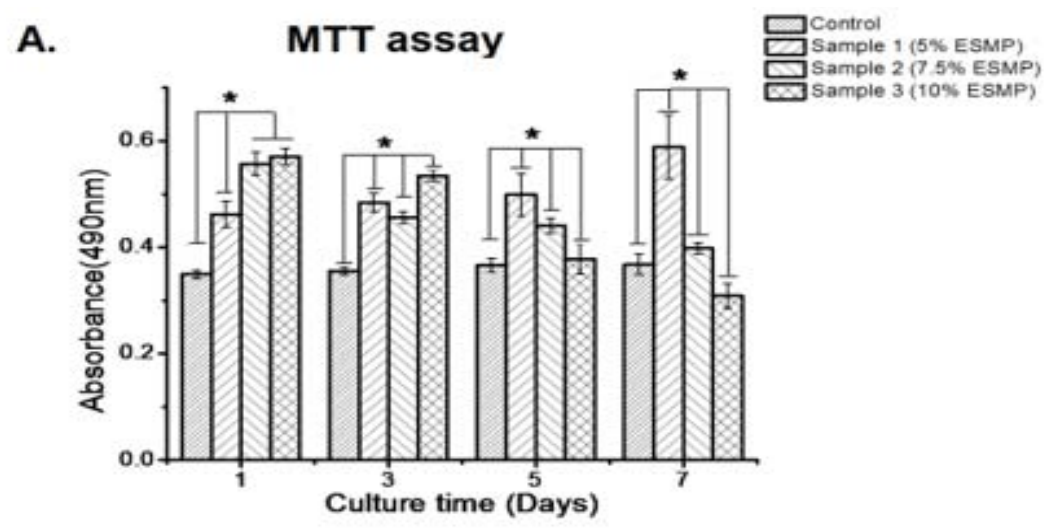

B.

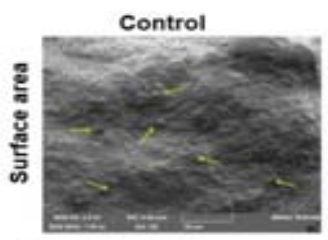

FESEM analysis
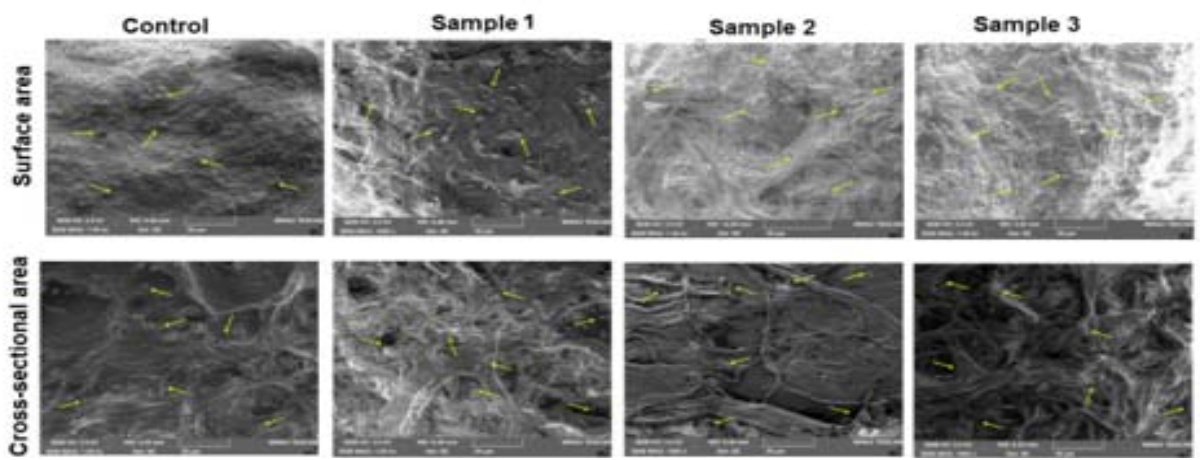

Figure 7: In vitro cell culture: (A) MTT assay and (B) FESEM images analysis of 3T3 mouse fibroblast cell-scaffold constructs. Yellow arrow indicated cell proliferation and neo-ECM formation. Here * indicated significant difference between the groups $(p<0.05)$.

AGDS where no hair-follicles were developed. Histological analysis of H\&E stained skin biopsies collected from the wound site confirmed completely healing and neo-skin layers regeneration of the acellular scaffold treated wounds (group II and group III) were (Figure 8C). On post-operative day 7 epidermal and dermal layers was formed in the groups covered with grating material, without any significant inflammation. On post-operative day 14, in group III (ESMP-AGDS) dense epidermal, dermal layer with follicle site were observed. The histopathological tests clearly demonstrated that ESMP modified acellular scaffold shows better wound healing, with fully regenerated skin (epidermal and dermal layer) with hair-follicles as compare to other collagenous products.

\section{Inflammatory and Immunogenic response}

During the wound healing inflammatory phase is one the phase: generation of macrophages or monocytes for the removal of dead tissue. However, prolonged inflammation at the wound site results slow wound healing and finally the rejection of grafting material from the implantation site [58-60]. Briefly, the inflammation occurs at the wound site were evaluated by using the following scale: 0 , little or no inflammation; 1, aggregates of inflammatory cells occupying less than $50 \%$ of the sample; and 2, aggregates of inflammatory cells occupying $50 \%$ or more of the sample. On post-operative day 7 , the inflammatory response was in all groups: Group I > Group II > Group III (Table 2), least inflammation occurred in Group III among all the groups. With the progression of time, on post-operative day 14, the inflammation was not shown in group II and III, while in the group
I, significant inflammatory cells were shown. Wounds with less or no inflammation were completely healed wounds, as observed in dermal graft treated (AGDS and ESMP-AGDS) group. (Table 1 and Figure 8C). However, the control group treated wounds shows some inflammation and poor healing rate. Other researcher also observed that the wounds having prolonged inflammatory response, shown poor wound healing $[61,62]$. Inflammation at wound site occurs due to the infection or pathogenic attack and results in induction of immune response: humoral (Ig) and cell-mediated response. Immunological testing of blood serum sample collected from treated animals showed no humoral immune response in group III and IV on post-operative day 7, (Table 3). On post-operative day 7, group I showed positive Igs and C 3 test: indicated in situ immune reaction occurs in the host body. However, after two-weeks of surgery the Igs and C3 level were significantly very low in all the groups, which indicates that the epithelization or wound coverage, reduced the pathogenic attack. CBC test of blood sample collected on postoperative day 7 and 14, revealed that the cell-mediated immune response (Figure 9). On post-operative day the 7 the total WBC: Group I> Group II> Group III. On day 14, WBC was still higher in group I, however in another group WBC significantly decreased. Lymphocytes counts were also reported high in group I as compared to the acellular scaffold treated groups i.e., II and III respectively. In literature, it was reported that the goat-collagen showed low in vivo immunogenicity [34,63,64]. Monocytes counts were also significantly very high in group I and II as compared to the group II and III. In group II and III the monocytes were very negligible, which supports 
A.

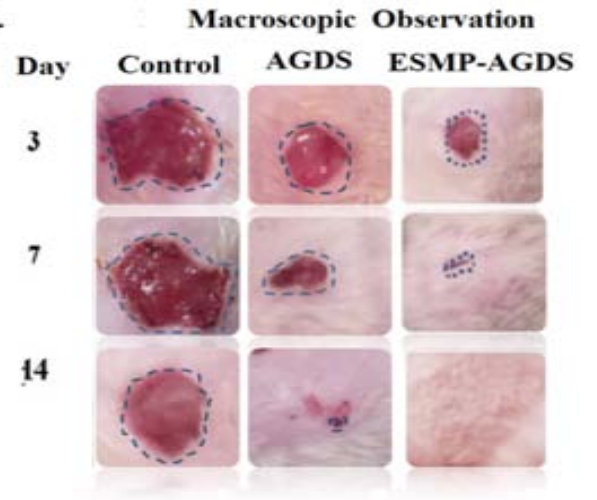

B. Wound healing rate

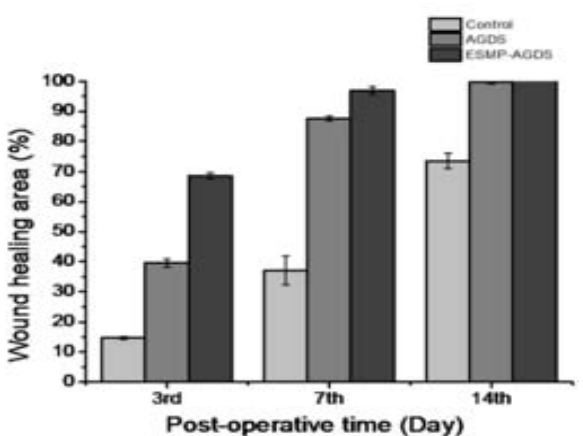

C.

Microscopic Observation

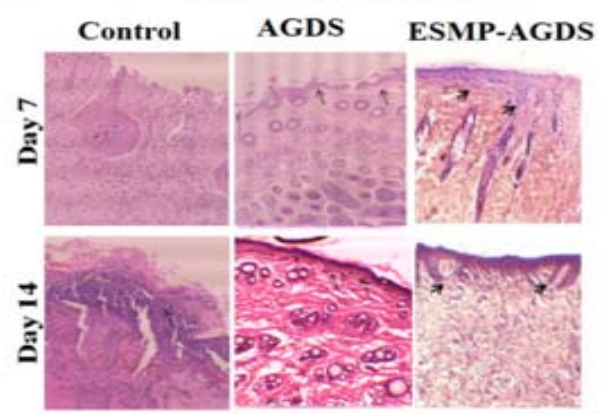

Figure 8: In vivo wound healing study of full-thickness excisional wound on albino mice- (A) wounds macroscopic observation, (B) Wound healing rate, and (C) Histomorphological analysis of $\mathrm{H} \& \mathrm{E}$ stained images of wound tissue biopsies at $10 \mathrm{X}$ magnification. Here ${ }^{*}$ indicated significant difference between the groups $(\mathrm{p}$ $<0.05)$.
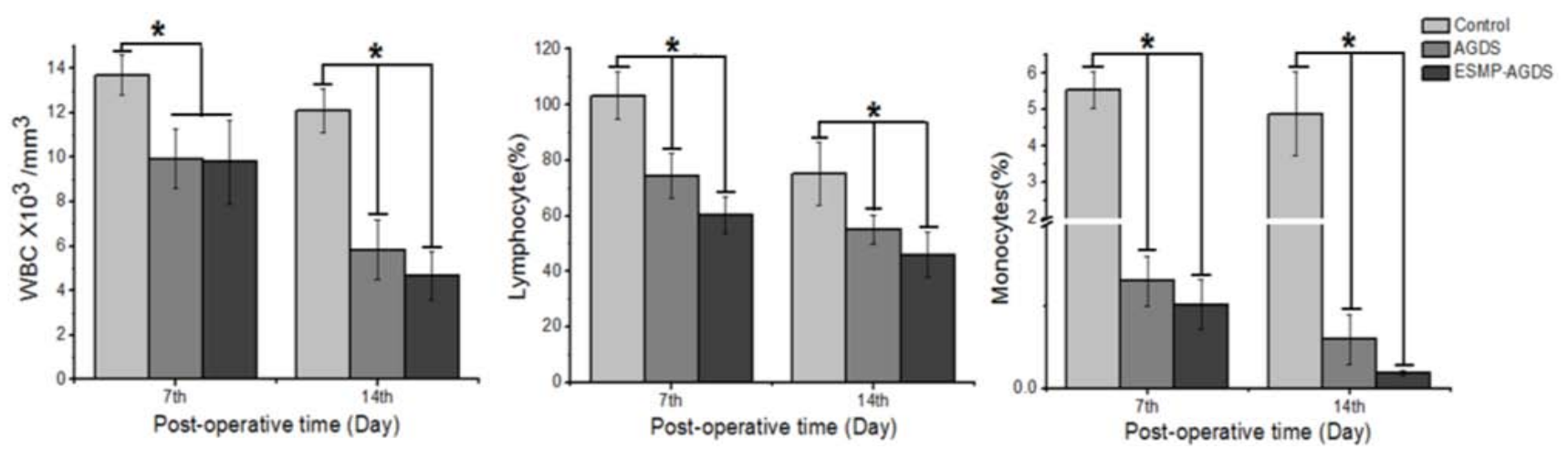

Figure 9: $\mathrm{CBC}$ analysis to measure the Host Cell mediate immune response in albino mice: $(\mathrm{A})$ white blood cell; (B) Monocyte count and (C) Lymphocyte count. Here * indicated significant difference between the groups $(p<0.05)$.

faster healing as compared to other groups. Thus, the outcomes of study of the fabricated ESMP-AGDS in vivo host response show negligible immunogenicity and inflammation (very low proliferation of WBC, monocytes and lymphocytes). ESM and acellular grafts has already been used as biological dressing for wound dressings and its constituents reported as a potential biomaterial for tissue engineering scaffold [3,65-67]. Kang and co-workers found that SEP-PCL blend fiber showed increased hydrophilicity, which results for better wound healing [68]. Chen and co-workers also prepared a nanocomposite by blending soluble Egg Membrane (EM) and polyurethane for the application of wound dressing [10]. Other researchers reported that the EM accelerated wound closure in the early stages of wound healing and have anti-inflammatory response over split-thickness skin graft donor sites $[8,69,70]$. SEP-SF scaffold supported the good cell attachment and proliferation in vivo condition without causing infection, inflammation, and/or tissue cell death [34]. In vivo animal study of SEP modified SF-PVA scaffold showed that the scaffolds are non-immunogenic and support tissue growth [49]. Li and coworkers found that EM/AgNPs could promote re-epithelialization, granulation tissue formation and wound healing with enhancing cell proliferation (more than 7 days $-88.6 \%$ ) in a murine full thickness skin wound model [71]. Thus, the Pre-clinical study showed that at low concentration (5\% ESMP), ESMP-AGDS, synergistically enhance the wound healing rate, full-thickness wound was completely healed 
and full thickness skin was regenerated, without any inflammatory response.

\section{Conclusion}

ESMP modified AGDS having 3D porous intact structure consisting of ECM (extra cellular matrix) components (e.g., collagen, GAGs, proteoglycans) was successfully fabricated and evaluated for wound healing application. 3T3 mouse fibroblast cells seeded over the ESMP-AGDS, revealed excellent cell viability, proliferation rate and adhesion in the scaffold. Pre-clinical full-thickness excisional wound study in albino mice, confirmed the ESMP modification enhance the healing capability of AGDS. ESMP-AGDS treated wounds were completely cured within 14 days and regenerated full thickness skin with hair-follicles. Thus, it has confirmed that ESMP coupled with AGDS shown the synergetic effect and results better healing as compared to the AGDS. Over all, the study proved that the scaffold modified with ESMP is a novel, cost-effective, biodegradable, biocompatible, non-toxic material. Hence, ESMP-AGDS should be a potentially candidate for large wound area coverage and applied for tissue engineering applications.

\section{Acknowledgement}

We grateful and thankful to Dr. N.C. Mishra (Department of Polymer and process engineering, IIT Roorkee, India) for providing lab scaffold fabrication; Professor Partha Roy (Department of Biotechnology, IIT Roorkee, India) for providing cell culture facilities and Professor A.K. Dinda (Department of Pathology, AIIMS, New Delhi, India) for their valuable suggestion. We also thankful to Professor S.C. Sharma (Department of Applied Sciences, IIT Roorkee, India) for their valuable guidance and suggestions. The financial assistance for this work by Indian Institute of Technology, Roorkee and Ministry of Human Resource Development (MHRD), Govt. of India, is gratefully acknowledged.

\section{References}

1. E Ohto-Fujita, T Konno, M Shimizu, K Ishihara, T Sugitate, J Miyake, et al. Hydrolyzed eggshell membrane immobilized on phosphorylcholine polymer supplies extracellular matrix environment for human dermal fibroblasts. Cell and tissue research. 2011; 345; 177-190.

2. M Baláž. Eggshell membrane biomaterial as a platform for applications in materials science. Acta biomaterialia. 2014; 10: 3827-3843.

3. F Yi, ZX Guo, LX Zhang, J Yu, Q Li. Soluble eggshell membrane protein: preparation, characterization and biocompatibility, Biomaterials. 2004; 25: 4591-4599.

4. Y Nys, J Gautron, MD McKee, JM Garcia-Ruiz, MT Hincke. Biochemical and functional characterisation of eggshell matrix proteins in hens. World's Poultry Science Journal. 2001; 57: 401-413.

5. PS Guru, S Dash. Sorption on eggshell waste-a review on ultrastructure, biomineralization and other applications. Advances in colloid and interface science. 2014; 209: 49-67.

6. MT Hincke, AM Bernard, ER Lee, CP Tsang, R Narbaitz. Soluble protein constituents of the domestic fowl's eggshell. British poultry science. 1992; 33: 505-516.

7. CMM Cordeiro, MT Hincke. Recent patents on eggshell: shell and membrane applications, Recent patents on food, nutrition \& agriculture. 2011; 3: 1-8.

8. JY Yang, SS Chuang, WG Yang, PK Tsay. Egg membrane as a new biological dressing in split-thickness skin graft donor sites: a preliminary clinical evaluation. Chang Gung medical journal. 2003; 26: 153-159.

9. JW Lu, Q Li, QL Qi, ZX Guo, J Yu. Surface engineering of poly (D, L-lactic acid) by entrapment of soluble eggshell membrane protein. Journal of Biomedical Materials Research Part A: An Official Journal of the Society for Biomaterials, the Japanese Society for Biomaterials, and the Australian Society for Biomaterials and the Korean Society for Biomaterials. 2009; 91: 701-707.

10. L Chen, J Kang, S Sukigara. Preparation and characterization of polyurethane/soluble eggshell membrane nanofibers. Bio-medical materials and engineering. 2014; 24: 1979-1989.

11. J Kang, M Kotaki, S Okubayashi, S Sukigara. Fabrication of electrospun eggshell membrane nanofibers by treatment with catechin. Journal of applied polymer science. 2010; 117: 2042-2049.

12. X Xiong, Q Li, JW Lu, ZX Guo, ZH Sun, J Yu. Fibrous scaffolds made by co-electrospinning soluble eggshell membrane protein with biodegradable synthetic polymers. Journal of Biomaterials Science, Polymer Edition. 2012; 23: $1217-1230$.

13. J Jia, G Liu, J Yu, Y Duan. Preparation and characterization of soluble eggshell membrane protein/PLGA electrospun nanofibers for guided tissue regeneration membrane. Journal of Nanomaterials. 2012; 2012: 25.

14. RA Kamel, JF Ong, E Eriksson, JP Junker, EJ Caterson. Tissue engineering of skin. Journal of the American College of Surgeons. 2013; 217: 533-555.

15. D Girard, B Laverdet, V Buhe, M Trouillas, K Ghazi, MM Alexaline, et al. Biotechnological management of skin burn injuries: challenges and perspectives in wound healing and sensory recovery. Tissue Engineering Part B: Reviews. 2017; 23: 59-82.

16. A Dhasmana, S Singh, S Kadian, L Singh. Skin Tissue Engineering: Principles and Advances. J Dermatol Skin. 2018; 1: 101.

17. MA Moore, B Samsell, G Wallis, S Triplett, S Chen, AL Jones, et al. Decellularization of human dermis using non-denaturing anionic detergent and endonuclease: a review. Cell and tissue banking. 2015; 16: 249-259.

18. RH Fu, YC Wang, SP Liu, TR Shih, HL Lin, YM Chen, et al. Decellularization and recellularization technologies in tissue engineering. Cell transplantation. 2014; 23: 621-630.

19. HJ Faust, Q Guo, JH Elisseeff. Cartilage Tissue Engineering, In Principles of Regenerative Medicine. Academic Press. 2019; 937-952.

20. A Dhasmana, L Singh, P Roy, NC Mishra. Honey incorporated antibacterial acellular dermal matrix for full-thickness wound healing. Ann Biotechnology. 2018; 3: 1011.

21. A Dhasmana, L Singh, P Roy, NC Mishra. Silk fibroin protein modified acellular dermal matrix for tissue repairing and regeneration. Materials Science and Engineering: C. 97: 2019; 313-324.

22. IV Yannas, E Lee, DP Orgill, EM Skrabut, GF Murphy. Synthesis and characterization of a model extracellular matrix that induces partial regeneration of adult mammalian skin. Proceedings of the National Academy of Sciences. 1989; 86: 933-937.

23. MC Ferreira, AO Paggiaro, C Isaac, N Teixeira Neto, GB Santos. Skin substitutes: current concepts and a new classification system. Rev Bras Cir Plást. 2011; 26: 696-702.

24. RV Shevchenko, SL James, SE James. A review of tissue-engineered skin bioconstructs available for skin reconstruction. Journal of the royal Society Interface. 2009; 7: 229-258.

25. SK Gupta, AK Dinda, PD Potdar, NC Mishra. Fabrication and characterization of scaffold from cadaver goat-lung tissue for skin tissue engineering applications. Materials Science and Engineering: C. 2013; 33: 4032-4038.

26. JA Boswick. The art and science of burn care. Aspen Pub. 1987.

27. G Vaccari, CH Panagiotidis, C Acin, S Peletto, F Barillet, P Acutis, et al. Stateof-the-art review of goat TSE in the European Union, with special emphasis on PRNP genetics and epidemiology. Veterinary research. 2009; 40: 48.

28. RE Strohbehn, LR Etzel, J Figgins, Biova LLC. Method of treatment using solubilized protein composition obtained from eggshell membrane. United States patent US 8,425,943. 2013

29. H Mohamed, BEI Lenjawi, MA Salma, S Abdi. Honey based therapy for the 
management of a recalcitrant diabetic foot ulcer. Journal of tissue viability. 2014; 23: 29-33

30. C Sharma, NC Mishra, AK Dinda. Synthesis and characterization of glycinemodified chitosan-gelatin-alginate composite scaffold for tissue engineering applications. J. Biomater. Tissue Eng. 2012; 2: 133-142.

31. $\mathrm{P}$ Lange, $\mathrm{K}$ Greco, L Partington, C Carvalho, S Oliani, MA Birchall, et al Ansari, Pilot study of a novel vacuum-assisted method for decellularization of tracheae for clinical tissue engineering applications, Journal of tissue engineering and regenerative medicine. 2017; 11: 800-811.

32. S Gautam, CF Chou, AK Dinda, PD Potdar, NC Mishra. Fabrication and characterization of $\mathrm{PCL} / g$ elatin/chitosan ternary nanofibrous composite scaffold for tissue engineering applications. J. Mater. Sci. 2014; 49: 10761089.

33. HM Powell, ST Boyce. Wound closure with EDC cross-linked cultured skin substitutes grafted to athymic mice. Biomaterials. 2007; 28: 1084-1092.

34. I Banerjee, D Mishra, T Das, S Maiti, TK Maiti. Caprine (goat) collagen: a potential biomaterial for skin tissue engineering. J. Biomater. Sci. Polym. Ed. 2012; 23: 355-373.

35. JH Yoo, JK Kim, HJ Yang, KM Park. Effects of egg shell membrane hydrolysates on UVB-radiation-induced Wrinkle formation in $\mathrm{SKH}-1$ hairless mice. Korean journal for food science of animal resources, 35: 2015; 58-70.

36. T Wang, XK Zhu, XT Xue, DY Wu. Hydrogel sheets of chitosan, honey and gelatin as burn wound dressings. Carbohydrate Polymers. 88: 2012; 75-83.

37. MK Sah, K Pramanik. Soluble-eggshell-membrane-protein-modified porous silk fibroin scaffolds with enhanced cell adhesion and proliferation properties. Journal of Applied Polymer Science. 2014; 131: 1-11.

38. BB Doyle, EG Bendit, ER Blout. Infrared spectroscopy of collagen and collagen-like polypeptides. Biopolymers: Original Research on Biomolecules. 1975; 14: 937-957.

39. MC Chang, J Tanaka. FT-IR study for hydroxyapatite/collagen nanocomposite crosslinked by glutaraldehyde. Biomaterials. 2002; 23: 4811-4818.

40. J Jia, Z Guo, J Yu, Y Duan. A new candidate for guided tissue regeneration: biomimetic eggshell membrane. Journal of Medical Hypotheses and Ideas. 2011; 5: 1-5.

41. J Kang, M Kotaki, S Okubayashi, S Sukigara. Fabrication of electrospun eggshell membrane nanofibers by treatment with catechin. Journal of applied polymer science. 2010; 117: 2042-2049.

42. T Nakano, N Ikawa, L Ozimek. Extraction of glycosaminoglycans from chicken eggshell. Poultry science. 2001; 80: 681-684

43. T Nakano, N Ikawa, L Ozimek. Chemical composition of chicken eggshell and shell membranes. Poultry Science. 2003; 82: 510-514.

44. Y Li, Y Ye, Y Fan, J Zhou, L Jia, B Tang, et al. Silver nanoprism-loaded eggshell membrane: a facile platform for in situ sers monitoring of catalytic reactions. Crystals. 2017; 7: 45.

45. IV Yannas, E Lee, DP Orgill, EM Skrabut, GF Murphy, GF Murphyt. Synthesis and characterization of a model extracellular matrix that induces partial regeneration of adult mammalian skin. Proceedings of the National Academy of Sciences. 1989; 86: 933-937.

46. CD Chin, K Khanna, SK Sia. A microfabricated porous collagen-based scaffold as prototype for skin substitutes. Biomedical Microdevices. 2008; 10 : 459-467.

47. P Tayalia, E Mazur, DJ Mooney. Controlled architectural and chemotactic studies of 3D cell migration. Biomaterials. 2011; 32: 2634-2641.

48. RM Reddy, A Srivastava, A Kumar. Monosaccharide-Responsive Phenylboronate-Polyol Cell Scaffolds for Cell Sheet and Tissue Engineering Applications. PLoS ONE. 2013; 8: e77861.

49. MK Sah, I Banerjee, K Pramanik. Eggshell Membrane Protein Modified Silk Fibroin-Poly Vinyl Alcohol Scaffold for Bone Tissue Engineering: In Vitro and In Vivo Study. InJournal of Biomimetics, Biomaterials and Biomedical Engineering. 2017; 32: 69-81.
50. JL Arias, MS Fernandez. Role of extracellular matrix molecules in shell formation and structure. World's Poultry Science Journal. 2001; 57: 349-357.

51. F Yi, ZX Guo, P Hu, ZX Fang, J Yu, Q Li. Mimetics of eggshell membrane protein fibers by electrospinning. Macromolecular rapid communications. 2004; 25: 1038-1043.

52. JL Arias, MS Fernandez, JE Dennis, AI Caplan. Collagens of the chicken eggshell membranes. Connective tissue research. 1991; 26: 37-45.

53. FG Torres, OP Troncoso, F Piaggio, A Hijar. Structure-property relationships of a biopolymer network: The eggshell membrane. Acta biomaterialia. 2010 6: 3687-3693.

54. Y Chen, W Dong, Y Xiao. Preparation and bioactivity of human hair keratincollagen sponge, a new type of dermal analogue. Journal of Southern Medical University. 2006; 26: 131-138.

55. WD Kim, T Min, SA Park, JH Park, GH Kim. A natural and biodegradable scaffold of electrospun eggshell membrane. WIT Transactions on Engineering Sciences. 2007; 57: 10

56. N Suguro, S Horiike, Y Masuda, M Kunou, T Kokubu. Bioavailability and commercial use of eggshell calcium, membrane proteins and yolk lecithin products, Egg nutrition and biotechnology. 2000; 50: 219-232.

57. QL Qi, Q Li, JW Lu, ZX Guo, J Yu. Preparation and characterization of soluble eggshell membrane protein/chitosan blend films. Chinese Journal of Polymer Science. 2009; 27: 387-392.

58. SA Livesey, DN Herndon, MA Hollyoak, YH Atkinson, A Nag. Transplanted acellular allograft dermal matrix. Potential as a template for the reconstruction of viable dermis. Transplantation. 1995; 60: 1-9.

59. HJ Wang, TM Chen, TY Cheng. Use of a Porcine Dermis Template to Enhance Widely Expanded Mesh Autologous Split-Thickness Skin Graft Growth. The Journal of Trauma: Injury, Infection, and Critical Care. 1997; 42: 177-182.

60. V Kumar, N Kumar, AK Gangwar, H Singh. Comparison of acellular small intestinal matrix (ASIM) and 1-ethyl-3-(3-dimethylaminopropyl) carbodiimide crosslinked ASIM (ASIM-EDC) for repair of full-thickness skin wounds in rabbits. Wound Medicine. 2014; 7: 24-33.

61. AK Gangwar, N Kumar, AK Sharma, KS Devi, M Negi, S Shrivastava, et al. Bioengineered acellular dermal matrix for the repair of full thickness skin wounds in rats. Trends in Biomaterials and Artificial Organs. 2013; 27: 67-80.

62. MWJ Ferguson, SO 'kane. Scar-free healing: from embryonic mechanisms to adult therapeutic intervention. Phil. Trans. R. Soc. Lond. B. 2004; 359: 839-850.

63. AK Lynn, IV Yannas, W Bonfield. Antigenicity and immunogenicity of collagen. Journal of Biomedical Materials Research Part B: Applied Biomaterials: An Official Journal of The Society for Biomaterials, The Japanese Society for Biomaterials, and The Australian Society for Biomaterials and the Korean Society for Biomaterials. 2004; 71: 343-354.

64. Y Lan, W Li, Y Jiao, R Guo, Y Zhang, W Xue, et al. Therapeutic efficacy of antibiotic-loaded gelatin microsphere/silk fibroin scaffolds in infected fullthickness burns. Acta biomaterialia. 2014; 10: 3167-3176.

65. $\mathrm{K}$ Maeda, $\mathrm{Y}$ Sasaki. An experience of hen-egg membrane as a biological dressing. Burns. 1982; 8: 313-316

66. DM Supp, ST Boyce. Engineered skin substitutes: practices and potentials. Clinics in dermatology. 23: 2005; 403-412.

67. SF Badylak, DO Freytes, TW Gilbert. Extracellular matrix as a biological scaffold material: Structure and function. Acta Biomaterialia. 2009; 5: 1-13.

68. J Kang, M Kotaki, S Okubayashi, S Sukigara. Fabrication of electrospun eggshell membrane nanofibers by treatment with catechin, Journal of applied polymer science. 2010; 117: 2042-2049.

69. L Chen, J Kang, S Sukigara. Preparation and characterization of polyurethane/soluble eggshell membrane nanofibers. Bio-Medical Materials and Engineering. 2014; 24: 1979-1989.

70. F Guarderas, Y Leavell, T Sengupta, M Zhukova, TL Megraw. Assessment of 
chicken-egg membrane as a dressing for wound healing. Advances in Skin and Wound Care. 2016; 29: 131-134.

71. Y Li, Y Ye, Y Fan, J Zhou, L Jia, B Tang, et al. Silver nanoprism-loaded eggshell membrane: a facile platform for in situ sers monitoring of catalytic reactions. Crystals. 2017; 7: 45 